\title{
SUPERAÇÃO DE DORMÊNCIA DE SEMENTES DE Capsicum baccatum var. pendulum (PIMENTA DEDO-DE-MOÇA)
}

\author{
Afonso Zucolotto Venturin ${ }^{1}$, José Carlos Lopes ${ }^{1}$, Pedro Ramon Manhone ${ }^{1}$, Rafael Fonseca \\ Zanotti $^{1}$, Sara de Oliveira Carvalho ${ }^{1}$ \\ ${ }^{1}$ Universidade Federal do Espírito Santo - E-mail: afonsozv@ hotmail.com
}

\section{RESUMO}

Objetivou-se avaliar o efeito de tratamentos químicos na superação da dormência de sementes de Capsicum baccatum var. pendulum. Os tratamentos utilizados foram: T1- água destilada; T2- Imersão em solução de citrato de sildenafila; T3- Imersão em solução de GA 3 ; T4Imersão em solução de SNP; T5- Imersão em solução de $\mathrm{KNO}_{3}$; T6- Imersão em solução de $\mathrm{HNO}_{3}$. O tratamento T3 apresentou médias superiores aos demais tratamentos. Sementes tratadas com $\mathrm{GA}_{3}$ apresentam maior vigor. As temperaturas de 30 e $20-30^{\circ} \mathrm{C}$ fazem as sementes externarem melhor seu vigor apresentando maior massa fresca, massa seca, comprimento da parte aérea e comprimento de raiz.

Palavras-chave: Germinação, índice de velocidade de germinação, vigor

\section{OVERCOMING SEEDS DORMANCY Capsicum baccatum var. pendulum}

\begin{abstract}
This study aimed to evaluate the effect of chemical treatments on breaking dormancy of seeds of Capsicum baccatum var. pendulum. The treatments were: T1 - distilled water; T2 immersion in a solution of sildenafil citrate; T3 - immersion in a solution of $\mathrm{GA}_{3}$; $\mathrm{T} 4$ - immersion in solution SNP; T5 - immersion in solution of $\mathrm{KNO}_{3}$; T6 - immersion in solution of $\mathrm{HNO}_{3}$. The T3 treatment showed an average higher than other treatments. Seeds treated with $\mathrm{GA}_{3}$ have greater vigor. Temperatures of $30{ }^{\circ} \mathrm{C}$ and $20-30{ }^{\circ} \mathrm{C}$ are the seeds expose best vigor with higher fresh weight, dry weight, shoot length and root length.
\end{abstract}

Keywords: Germination, germination speed index, vigor 


\section{INTRODUÇÃO}

As pimenteiras são espécies pertencentes ao gênero Capsicum e são cultivadas em todas as regiões do Brasil, sendo consumidas frescas ou processadas pela indústria de alimentos. Os principais estados brasileiros produtores são Minas Gerais, Goiás e São Paulo. A espécie de pimenta Capsicum baccatum var. pendulum, conhecida popularmente como dedo-de-moça é uma das mais consumidas no Brasil (CARVALHO et al., 2009); é uma espécie que apresenta dificuldades de propagação devido à dormência de suas sementes (CARNEIRO et al., 2010).

As sementes são consideradas dormentes quando mesmo viáveis e sob condições favoráveis são incapazes de germinarem (FINCH-SAVAGE \& LEUBNER-METZGER, 2006). A dormência é considerada um mecanismo de adaptação das sementes contra modificações no ambiente que impedem ou dificultam as reações metabólicas normais durante o processo de desenvolvimento da semente. A retomada do crescimento do embrião só é restabelecida após a ação de um estímulo ambiental específico (MARCOS FILHO, 2005). Vários fatores estão envolvidos na regulação da dormência das sementes, dentre eles os hormônios, como o ácido abscísico
(ABA), as giberelinas (GAs), etileno, citocininas e ácido salicílico (BEWLEY, 1997; ZHOU et al., 1998; RAMAIH et al., 2003; CHANDRA et al., 2007; CARRERA et al., 2008; HOLDSWORTH et al., 2008). Além desses, há também fatores ambientais tais como luminosidade e temperatura, que modificam a sensibilidade ou a produção de hormônios como ABA e GAs (BEWLEY, 1997).

A temperatura em que ocorre a germinação das sementes é outro fator que influencia tal processo, tanto sob a germinação final como sob a velocidade em que ocorre a germinação. A temperatura interfere tanto na dinâmica da absorção de água como nos limites e velocidade das reações bioquímicas, além dos processos fisiológicos que determinam todo o processo germinativo (CARVALHO \& NAKAGAWA, 2000; MARCOS FILHO, 2005). Sendo assim, objetivou-se com esse trabalho avaliar o efeito de tratamentos químicos e da temperatura de germinação na superação da dormência de sementes de Capsicum baccatum var. pendulum.

\section{MATERIAL E MÉTODOS}

$\mathrm{O}$ experimento foi conduzido no Laboratório de Análise de Sementes (LAS) do Centro de Ciências Agrárias da 
Universidade Federal do Espírito Santo (CCA UFES), Alegre, ES.

O material vegetal utilizado foram sementes de Capsicum baccatum var. pendulum, provenientes de frutos maduros obtidos no campus do Centro de Ciências Agrárias da Universidade Federal do Espírito Santo, Alegre-ES. O beneficiamento dos frutos foi realizado no local do experimento. Para a extração das sementes, os frutos foram seccionados paralelamente ao seu eixo transversal. Em seguida, as sementes foram postas para secar, durante 24 horas, sobre papel toalha em condições de laboratório (28 $\pm 2{ }^{\circ} \mathrm{C}$ ) e, então realizada a determinação do grau de umidade do lote (Brasil 2009).

As sementes foram acondicionadas em frascos de vidro, com tampa de metal rosqueável, os quais foram devidamente identificados e mantidos em geladeira, com temperatura controlada de $5 \pm 2{ }^{\circ} \mathrm{C}$ e $30 \%$ de umidade relativa (U.R.) onde permaneceram armazenadas por sete dias até o início do teste de germinação e realizadas avaliações da qualidade física e fisiológica das sementes. Os tratamentos utilizados foram:

T1- água destilada;

T2- Imersão em solução de citrato de sildenafila a $500 \mathrm{mg} / \mathrm{L}$ durante 10 minutos;

T3- Imersão em solução de $\mathrm{GA}_{3}$ a $500 \mathrm{mg} / \mathrm{L}$ durante 10 minutos;
T4- Imersão em solução de SNP a $10 \mu \mathrm{mol} / \mathrm{L}$ durante 10 minutos;

T5- Imersão em solução de $\mathrm{KNO}_{3}$ a 10\%durante 15 minutos;

T6- Imersão em solução de $\mathrm{HNO}_{3}$ a $67 \%$ durante 10 minutos.

As sementes foram colocadas para germinar em placa de Petri com quatro repetições de 25 sementes cada sob três diferentes temperaturas: 20,30 e $20-30{ }^{\circ} \mathrm{C}$. As sementes e os frutos foram avaliados em relação:

Morfologia dos frutos

Os frutos foram avaliados em relação aos seguintes caracteres: comprimento do fruto $(\mathrm{mm})$, largura do fruto $(\mathrm{mm})$, massa do fruto $(\mathrm{g})$, comprimento da semente $(\mathrm{mm})$, largura da semente (mm); avaliados com auxílio de uma régua milimetrada.

Teor de umidade (TU)

Determinado pelo método de estufa, regulada a $105 \pm 3{ }^{\circ} \mathrm{C}$ por 24 horas (Brasil 2009), utilizando-se duas amostras de 40 sementes, as quais foram pesadas em balança analítica com precisão de 0,0001 g e os resultados expressos em porcentagem.

\section{Massa de mil sementes (MMS)}

Calculada de acordo com Brasil (2009); foram utilizadas oito subamostras de 100 sementes provenientes da porção "Semente 
Pura" e, calculado a variância, o desvio padrão e o coeficiente de variação dos valores obtidos das pesagens de cada sub amostra.

Teste de primeira contagem (TPC)

Conduzido juntamente com o teste de germinação, computando-se o percentual médio de plântulas no sétimo dia após a semeadura, conforme Brasil (2009).

Teste de germinação (TG)

Foi realizado em câmara de germinação do tipo BOD sob três diferentes temperaturas, com fotoperíodo de 8 horas de luz e 16 horas de escuro. A semeadura foi realizada em placa de Petri com quatro repetições de 25 sementes. As avaliações foram realizadas conforme as Regras para Análise de Sementes (Brasil 2009).

Índice de velocidade de germinação (IVG)

Calculado pelo somatório do número de sementes germinadas a cada dia, dividido pelo número de dias decorridos entre a semeadura e a germinação, de acordo com a fórmula definida por Maguire (1962):

$$
I V G=\frac{N_{1}}{D_{1}}+\frac{N_{2}}{D_{2}}+\cdots+\frac{N_{n}}{D_{n}}
$$

Em que: $I V G=$ Índice de Velocidade de Germinação; N1...n = número de sementes germinadas no dia $1 \ldots \mathrm{n}$; e D1...n = dias para ocorrência da germinação.

Comprimento de plântulas normais

As plântulas foram medidas com auxílio de régua milimetrada no décimo quarto dias após a semeadura e final do teste de germinação.

Teste de massa fresca e massa seca

Obtida a partir da pesagem, em balança de precisão, da massa fresca da parte aérea e da raiz das plântulas; e a massa seca obtida através da pesagem da massa fresca após secagem em estufa a $75^{\circ} \mathrm{C}$ por 72 horas, de acordo com metodologia descrita por Bias et al. (1999).

O delineamento do experimento foi inteiramente casualizado em parcelas subdivididas no espaço. As parcelas correspondem as temperatura de 20, 30 e 20$30^{\circ} \mathrm{C}$, e as subparcelas aos métodos de superação da dormência (T1, T2, T3, T4, T5 e T6).

Para os dados obtidos neste estudo, a condição da normalidade não foi garantida para as variáveis, por isso foi utilizado teste não-paramétrico Friedman em nível de 5\% de probabilidade, utilizando o programa computacional $\mathrm{R}$ (R DEVELOPMENT CORE TEAM, 2013).

\section{RESULTADOS E DISCUSSÃO}

A caracterização morfológica dos frutos de Capsicum baccatum, como massa do fruto, comprimento do fruto, largura do fruto, comprimento da semente largura da semente estão representadas na Tabela 1. 
O teste de pureza física, teor de umidade e massa de mil sementes do lote de sementes estão representados na Tabela 2.

As sementes do tratamento T6 (imersão em solução de $\mathrm{HNO}_{3}$ a $67 \%$ durante 10 minutos) foram descartadas devido à contaminação por fungos, de todas as repetições, independente da temperatura. O material contaminado, não utilizado no teste de germinação, foi encaminhado ao laboratório de Fitopatologia do Centro de Ciências Agrárias da Universidade Federal do Espírito Santo para identificação dos fungos. $\mathrm{O}$ resultado do teste identificou os fungos como pertencentes aos gêneros Aspergillus sp. e Penicillium sp.

A associação do fungo com a semente propicia a sobrevivência do patógeno por longos períodos e causa prejuízos como acelerar o processo de deterioração das sementes, prejudicando assim a germinação. A ocorrência de gêneros de fungos em sementes em plantas medicinais, condimentares e aromáticas no Brasil é grande, porém, podem-se destacar os gêneros Aspergillus, Penicillium, como os de maior frequência sendo considerados contaminantes de sementes (KRUPPA \& RUSSOMANNO, 2011).

A germinação das sementes (Tabela 3) tratadas com $\mathrm{GA}_{3}$ (T3) alcançaram resultados superiores quando comparada aos demais tratamentos, independente da temperatura. Este regulador vegetal aumenta a germinação de sementes, garantindo um estande uniforme (LOPES \& SOUZA, 2008); o mesmo resultado foi encontrado por Rogis et al. (2004) em Trisacum dactyloides e por Phillips et al. (2003) em Perideridia gairdneri. As sementes imersas no tratamento T5 $\left(\mathrm{KNO}_{3}\right)$ não apresentaram diferença àquelas imersas no tratamento $\mathrm{T} 3\left(\mathrm{GA}_{3}\right)$. A aplicação de KNO3 é recomendada por Brasil (2009) para que ocorra uma melhor germinação das sementes do gênero Capsicum.

As sementes imersas nos tratamentos T1, T2 e T5 germinadas em temperatura de $30{ }^{\circ} \mathrm{C}$ apresentaram valores inferiores de germinação dentro de cada tratamento nas diferentes temperaturas, talvez pelo fato desta não ser a temperatura ótima para as sementes desta espécie.

No presente trabalho, a imersão das sementes durante 10 minutos em $\mathrm{HNO}_{3}$, mostrou um resultado satisfatório, apresentando 36\% de germinação. Enquanto que, a imersão das sementes durante 15 minutos em solução de $\mathrm{KNO}_{3}$ não apresentou diferença na porcentagem de germinação quando comparada com a testemunha.

$\mathrm{O}$ efeito do ácido giberélico sobre o 


\section{SUPERAÇÃO DE DORMÊNCIA DE SEMENTES DE Capsicum baccatum var.pendulum (PIMENTA DEDO-DE-MOÇA)}

alongamento celular e crescimento foi observado por diversos autores, não foi confirmado neste trabalho. Os resultados podem ser atribuídos também às concentrações do ácido giberélico empregadas, ou mesmo ao tempo de submersão das sementes.
$\left(\mathrm{GA}_{3}\right)$ apresentou média superior aos demais tratamentos para a superação de dormência, sendo que não mostrou diferença entre as temperaturas. Os demais tratamentos $(\mathrm{T} 1, \mathrm{~T} 2$, T4 e T5), também não apresentaram diferenças quando submetidos a diferentes temperaturas.

Para o TPC (Tabela 4), o tratamento T3

Tabela 1. Massa do fruto (MFR), comprimento do fruto (CF), largura do fruto (LF), comprimento da semente (CS) e largura da semente (LS).

\begin{tabular}{ccccc}
\hline MFR $(\mathrm{g})$ & CF $(\mathrm{cm})$ & LF $(\mathrm{cm})$ & CS $(\mathrm{mm})$ & LS $(\mathrm{mm})$ \\
\hline 4,7741 & 6,0 & 1,5 & 4 & 3,9 \\
\hline
\end{tabular}

Tabela 2. Pureza física, teor de umidade e massa de mil sementes.

\begin{tabular}{ccc}
\hline Pureza física $(\%)$ & Teor de umidade $(\%)$ & Massa de mil sementes $(\mathrm{g})$ \\
\hline 93,7 & 7,83 & 3,291 \\
\hline
\end{tabular}

Tabela 3. Germinação (\%) das sementes de $C$. baccatum submetidas aos métodos de superação de dormência nas três diferentes temperaturas.

\begin{tabular}{cccc}
\hline \multirow{2}{*}{ Tratamento } & \multicolumn{3}{c}{ Temperatura $\left({ }^{\circ} \mathrm{C}\right)$} \\
\cline { 2 - 4 } & 20 & 30 & $20-30$ \\
\hline T1 & $17 \mathrm{BCa}$ & $6 \mathrm{BCb}$ & $19 \mathrm{Ba}$ \\
T2 & $21 \mathrm{BCa}$ & $5 \mathrm{Cb}$ & $21 \mathrm{Ba}$ \\
T3 & $51 \mathrm{Aa}$ & $70 \mathrm{Aa}$ & $65 \mathrm{Aa}$ \\
T4 & $10 \mathrm{Ca}$ & $14 \mathrm{Ba}$ & $20 \mathrm{Ba}$ \\
T5 & $40 \mathrm{ABa}$ & $6 \mathrm{BCb}$ & $36 \mathrm{ABa}$ \\
\hline
\end{tabular}

Médias seguidas da mesma letra maiúscula em colunas e minúscula em linha, não diferem entre si em nível de 5\% de probabilidade pelo teste de Friedman.

Tabela 4. Teste de primeira contagem (TPC) em porcentagem, dos métodos de superação de dormência nas três diferentes temperaturas.

\begin{tabular}{crcr}
\hline \multirow{2}{*}{ Tratamento } & \multicolumn{3}{c}{ Temperatura $\left({ }^{\circ} \mathrm{C}\right)$} \\
\cline { 2 - 4 } & 20 & 30 & $20-30$ \\
\hline T1 & $3 \mathrm{Ba}$ & $0 \mathrm{Ba}$ & $0 \mathrm{Ba}$ \\
T2 & $0 \mathrm{Ca}$ & $2 \mathrm{Ba}$ & $1 \mathrm{Ba}$ \\
$\mathrm{T} 3$ & $27 \mathrm{Aa}$ & $40 \mathrm{Aa}$ & $38 \mathrm{Aa}$ \\
$\mathrm{T} 4$ & $1 \mathrm{Ca}$ & $1 \mathrm{Ba}$ & $0 \mathrm{Ba}$ \\
$\mathrm{T} 5$ & $7 \mathrm{Ba}$ & $2 \mathrm{Ba}$ & $1 \mathrm{Ba}$ \\
\hline
\end{tabular}

Médias seguidas da mesma letra maiúscula em colunas e minúscula em linha, não diferem entre si em nível de 5\% de probabilidade pelo teste de Friedman. 
Esses resultados demonstram o efeito da giberelina na promoção da germinação, e no controle de vários aspectos, desde a ativação do crescimento vegetativo do embrião, o enfraquecimento da camada do endosperma que envolve o embrião e restringe seu crescimento, até a mobilização das reservas energéticas do endosperma. A aplicação de giberelinas também estimula a produção de numerosas hidrolases, como a $\alpha$ amilase, conforme descrito em células da camada de aleurona (TAIZ \& ZEIGER, 2013).

O tratamento $\mathrm{T} 3 \mathrm{fez}$ com que as sementes apresentassem IVG superior quando comparados com os demais tratamentos (Tabela 5), porém não apresentaram diferenças quando observadas as temperatura as quais foram testadas. Ferreira et al. (2005) trabalhando com sementes de Passiflora alata Curtis verificou que o índice de velocidade de germinação das sementes tratada com $\mathrm{GA}_{3}$ foi maior quando comparado aos demais tratamentos.

Segundo Marcos Filho (2005), a temperatura pode afetar as reações bioquímicas que determinam todo o processo germinativo, uma vez que é responsável por ativar sistemas enzimáticos específicos.

A diferença da temperatura só foi observada nas sementes do tratamento imerso em água destilada somente (T1), onde a maior temperatura $\left(30{ }^{\circ} \mathrm{C}\right)$ apresentou menor velocidade de germinação, indicando que essa pode ter inibido seu desenvolvimento. Esse efeito da temperatura na velocidade de germinação das sementes provavelmente está ligado à ativação, e, ou, inibição das processos enzimáticos ligados a esse fenômeno. As enzimas apresentam atividades diferentes em determinadas temperaturas, sendo que em temperaturas extremas, pode ocorrer a desnaturação e sua atividade pode ser nula, ou seja, ocorre a degradação (LARCHER 2000; COSTA et al., 2010), principalmente pelo fato da temperatura poder atuar tanto como fator de quebra de dormência, como no controle da germinação de sementes.

Somente as sementes do tratamento T3 apresentaram plântulas normais. O comprimento da raiz (CR), o comprimento da parte aérea (CPA), a massa fresca (MF) e a massa seca (MS) das plântulas estão representados na Tabela 6. Apesar das plântulas do tratamento T3 não apresentarem diferença na germinação e índice de velocidade de germinação, o crescimento da raiz foi inibido sob temperatura alternada de 20-30 ${ }^{\circ} \mathrm{C}$; fato não observado no comprimento da parte aérea (CPA), massa fresca (MF) e massa seca (MS) das plântulas. 
Tabela 5. Índice de velocidade de germinação (IVG) das sementes submetidas aos métodos de superação de dormência nas três diferentes temperaturas.

\begin{tabular}{cccc}
\hline \multirow{2}{*}{ Tratamento } & \multicolumn{3}{c}{ Temperatura $\left({ }^{\circ} \mathrm{C}\right)$} \\
\cline { 2 - 4 } & 20 & 30 & $20-30$ \\
\hline T1 & $0,42 \mathrm{Ca}$ & $0,12 \mathrm{Bb}$ & $0,39 \mathrm{Ba}$ \\
T2 & $0,45 \mathrm{Ca}$ & $0,14 \mathrm{Ba}$ & $0,43 \mathrm{Ba}$ \\
T3 & $1,75 \mathrm{Aa}$ & $2,29 \mathrm{Aa}$ & $2,70 \mathrm{Aa}$ \\
T4 & $0,25 \mathrm{Ca}$ & $0,34 \mathrm{Ba}$ & $0,42 \mathrm{Ba}$ \\
T5 & $1,04 \mathrm{ABa}$ & $0,17 \mathrm{Ba}$ & $0,80 \mathrm{Ba}$ \\
\hline
\end{tabular}

Tabela 6. Comprimento da raiz (CR), comprimento da parte aérea $(\mathrm{CPA})(\mathrm{cm})$, massa fresca $(\mathrm{MF})$ e massa seca das plântulas (MS) (g) submetidas ao tratamento GA3 durante 10 minutos (T3) em diferentes temperaturas.

\begin{tabular}{ccccc}
\hline \multirow{2}{*}{ Temperatura $\left({ }^{\circ} \mathrm{C}\right)$} & \multicolumn{4}{c}{$\mathrm{GA}_{3}$} \\
\cline { 2 - 5 } & $\mathrm{CR}$ & $\mathrm{CPA}$ & $\mathrm{MF}$ & $\mathrm{MS}$ \\
\hline 20 & $11,02 \mathrm{~A}$ & $24,67 \mathrm{~A}$ & $11,07 \mathrm{~A}$ & $19,15 \mathrm{~A}$ \\
$20-30$ & $6,08 \mathrm{~B}$ & $37,12 \mathrm{~A}$ & $14,25 \mathrm{~A}$ & $22,02 \mathrm{~A}$ \\
30 & $14,22 \mathrm{~A}$ & $32,25 \mathrm{~A}$ & $13,57 \mathrm{~A}$ & $22,67 \mathrm{~A}$ \\
\hline
\end{tabular}

Médias seguidas da mesma letra maiúscula em colunas e minúscula em linha, não diferem entre si em nível de 5\% de probabilidade pelo teste de Friedman.

\section{CONCLUSÕES}

Sementes tratadas com GA3 apresentam maior vigor.

Sementes de C. baccatum germinam nas temperaturas de 20,30 e $20-30^{\circ} \mathrm{C}$.

\section{REFERÊNCIAS BIBLIOGRÁFICAS}

ALI-RACHEDI， S.; BOUINOT， D.; WAGNER, M.; BONNET, M.; SOTTA, B.; GRAPPIN, P.; JULLIEN, M. 2004. Changes in endogenous abscisic acid levels during dormancy release and maintenance of mature seeds: studies with the Cape Verde Islands ecotype, the dormant model of Arabidopsis thaliana. Planta, Berlin, v. 219, n. 3, p. 479-488.

BEWLEY, J. D. 1997. Seed germination and dormancy. Plant Cell, Waterbury, v. 9, n. 7, p. 1055-1066.

BIAS, A. L. F.; TILLMANN, M. A. A.; VILLELA, F. A.; ZIMMER, G. J. 1999. Métodos para avaliação da qualidade fisiológica de sementes de feijão vigna. Scientia Agrícola, Piracicaba, v. 56, n. 3, p. 651-660. 
BRASIL. Ministério da Agricultura, Pecuária e Abastecimento. Secretaria de Defesa Agropecuária. 2009. Regras para análise de sementes. Brasília, DF: MAPA/ ACS.

CARRERA, E.; HOLMAN, T.; MEDHURST, A.; DIETRICH, D.; FOOTITT, S.; THEODOULOU, F. L.; M. J. HOLDSWORTH. 2008. Seed afterripening is a discrete developmental pathway associated with specific gene networks in Arabidopsis. The Plant Journal, Oxford, v. 53, n. 2, p. 214-224.

CARNEIRO, G. G.; BARBOSA, J. A.; SILVA, E. O.; GOIS, G. C.; LUCENA, H. H.; ALVES, E. U. 2010. Germinação de pimentas cambuci submetidas à superação de dormência em água quente. Bioscience Journal, Uberlândia, v. 26, n. 6, p. 882885.

CARVALHO, N. M.; NAKAGAWA, J. 2012. Sementes: ciência, tecnologia e produção. Jaboticabal: FUNEP. 590p.

CARVALHO, S. I. C.; RIBEIRO, C. S. C; HENZ, G. P.; REIFSCHNEIDER, F. J. B. 2009. 'BRS Mari': nova cultivar de pimenta dedo-de-moça para processamento. Horticultura Brasileira, Brasília, v. 27, n. 4, p. 571-573.

CHANDRA, A.; ANAND, A.; DUBEY, A. 2007. Effect of salicylic acid on morphological and biochemical attributes in cowpea. Journal of Environmental Biology, Lucknow, v. 28, n. 2, p. 193196.

COSTA, F. P.; MARTINS, L. D.; LOPES, J. C. 2010. Frequência de germinação de sementes de crambe (Crambe abyssinica Hochst.) sob influência de tratamentos pré-germinativos e de temperaturas. Nucleus, Ituverava, v.7, n. 2, p 185-193. FERREIRA, G.; OLIVEIRA, A.; RODRIGUES, J. D.; DIAS, G. B.; DETONI, A. M.; TESSER, S. M.; ANTUNES, A. M. 2005. Efeito de arilo na germinação de sementes de Passiflora alata Curtis em diferentes substratos e submetidas a tratamentos com giberelina.

\section{Revista Brasileira de Fruticultura.} Jaboticabal, v. 27, n. 2, p. 277-280.

FILGUEIRA, F. A. R. 2008. Novo manual de olericultura. Viçosa-MG: UFV.

FINCH-SAVAGE W. E.; LEUBNERMETZGER G. 2006. Seed dormancy and the control of germination. New Phytologist, Lancaster, v. 171, n. 3, p. 501-523.

HOLDSWORTH, M. J. BENTSINK, L.; WIM J. J. SOPPE. 2008. Molecular networks regulating Arabidopsis seed maturation, after ripening, dormancy and germination. New Phytologist, Oxford, v. 179, n. 1, p. 33-54. 
KRUPPA, P. C.; RUSSOMANNO, O. M. R. 2011. Fungos em plantas medicinais, aromáticas e condimentares - solo e semente. Biológico, São Paulo, v. 73, n. 1, p. 33-38.

LARCHER, W. 2000. Ecofisiologia Vegetal. São Carlos: RiMa Artes e Textos, 531p.

LOPES, H. M.; SOUZA, C. M. 2008. Efeitos da giberelina e da secagem no condicionamento osmótico sobre a viabilidade e o vigor de sementes de mamão (Carica papaya L.). Revista Brasileira de Sementes, Londrina, v. 30, n. 1, p. 181-189.

MAGUIRE, J. D. 1962. Speed of germination-aid in selection and evolution for seedling emergence and vigor. Crop Science, Madison, v. 2, n. 2, p. 176-177.

MARCOS FILHO J. 2005. Fisiologia de sementes de plantas cultivadas. Piracicaba: FEALQ. 495p.

PHILLIPS, N.; DROST, D.; VARGA, W. 2003. Chemical treatments enhance seed germination in Perideridia gairdneri. Acta Horticulturae, Leuven, n. 618, p. 477-482.

R DEVELOPMENT CORE TEAM. 2011. R:

A language and environment for statistical computing. Vienna: R Foundation for Statistical Computing, 2011.
RAMAIH, S.; GUEDIRA, M.; PAULSEN, G. M. 2003. Relationship of indoleacetic acid and tryptophan to dormancy and preharvest sprouting of wheat. Functional Plant Biology, Collingwood, v. 30, n. 9, p. 939-945.

REIFSCHNEIDER, F. J. B. 2000. Capsicum: Pimentas e Pimentões no Brasil. Brasília, DF: EMBRAPA Comunicação para Transferência de Tecnologia/ EMBRAPA Hortaliças. $133 \mathrm{p}$.

ROGIS, C.; GIBSON, L. R.; KNAPP, A. D.; HORTON, R. 2004. Enhancing germination of eastern gama grass seed with stratification and gibberelic acid. Crop Science, Madison, v. 44, n. 2, p. 549-552.

TAIZ, L.; ZEIGER, E. 2013. Fisiologia vegetal. Porto Alegre: Artmed. 719p.

ZHOU, L.; Jang, J.; Jones, T. L.; Sheen, J. 1998. Glucose and ethylene signal transduction crosstalk revealed by an Arabidopsis glucose-insensitive mutant. Plant Biology, Washington v. 95, n. 17, p.10294-10299.
Recebido em: 23/08/2013 Aceito para publicação em: 10/08/2014 